\title{
The Study of English Writing Teaching from the Perspective of Language Memetics
}

\author{
Juanjuan Hou \\ School of Foreign Languages, Yan'an University
}

Keywords: Language memetics; English writing; Teaching research

\begin{abstract}
Writing is a difficult point in English teaching, and good writing ability needs the accumulation of English quality. As a result, teachers have spent plenty of time in teaching English writing for a long time. However, at present, the traditional teaching method of English writing is always based on mechanical imitation. For example, teachers provide students with model essays and encourage them to write their articles with similar materials, which is hard to stimulate the students' learning interest if things go on like this for a long time. Due to this situation, the author of this paper tries to put forward the English writing teaching method from the perspective of language memetics, and hopes to change the attitude towards learning English writing. In this way, the students' comprehensive English ability can also be improved.
\end{abstract}

\section{Introduction}

Language memetics was first put forward by an English scholar, and it was not only adapted to the language teaching at the very early age. Until 2003, the famous Chinese educator professor He Ziran had introduced this theory into China and applied it to the language teaching from then on. In fact, from the concept of memetics we can see the fact that anything copied from one person to another can be called a "meme". So we can use the concept of "meme" to explain the linguistic phenomenon. This process of explanation can also be understood as a process of exploring the essence of language, which will help us learn the language more easily. Therefore, how to apply the memetics to English writing teaching has become a fact we are facing.

\section{The Literature Review about Language Memetics at Present}

The Foreign Relevant Research about Language Memetics. The concept of "meme" was first put forward by professor Richard Dawkins in Oxford. In The Selfish Gene, he emphasized that genes follow the law of "survival of the fittest" and survive through competing with others. This book summarized the basic theory of memetics in detail from the perspective of biology. Although at that moment the memetics was only a frame, its theory still laid a foundation for its latter application. In addition, the English psychologist Blackmore combined the theory of memetics with the various kinds of studies at that time. Due to Blackmore's efforts, the memetics can be truly applied to the language teaching. In her book Meme Machines, she made a detailed demonstration about these theories. At the same time, she also put forward an opinion that essentially speaking, the process of human cognition is just the process of imitation.

In addition, in 1994, the foreign linguist March also made his demonstration about the fact that how language memetics is guiding other people's behavior in his works. What is worthy to be mentioned is that all his theories are put forward on the basis of the transmission characteristics of memetics. From the above analysis, there is a good reason for us to say that the foreign research on language memetics is ahead of that at home.

Then let's turn to the year 2005. Doctor Kate Distin published his book The Selfish Memes through the help of CUP (Cambridge University Press). In this book, she illuminated the effect of memetics on exploring the origin of languages, which laid a solid foundation for deepening the application of memetics to the field of language education.

The Relevant Research about Language Memetics at Home. Nowadays, there are many scholars at home who are trying to do some researches on language memetics. The reason for this 
fact is that they want to use the relative concept of memetics to explore the linguistic phenomenon. Relatively speaking, the following points of view are more perfect. First, professor He explored the application of memetics on the language teaching in many of his works, which has become the preliminary guideline of applying the memetics to the English writing teaching.

Second, in Memetics and Social Pragmatics, professor He gave a detailed analysis of the memetic phenomenon in language and he also gave a clear explanation of this concept by using the network buzzwords. With the development of other scholars' relative studies, many ideas of using memetics to study the foreign language teaching have been put forward. However, these studies mainly rest on the theoretical stage, and there is little research on the combination of memetics and actual foreign language classroom teaching. Meanwhile, there is no such study about the English writing teaching from the perspective of the replication of memes and their communication characteristics. As a result, this paper will have some constructive meaning for the study in this field. Generally speaking, for the research of foreign language study at home, the language memetics is still in its nascent stage, and it also needs the efforts of relevant scholars.

\section{The Limiting Factors of the Application of Memetics to English Writing Teaching}

The Single Teaching Method. As we have discussed in the previous part, the English writing teaching at present still takes the way of imitating the model essays. Generally, teachers will choose some characteristic passages in structure and let students recite them, or they will let students grasp the "universal sentences". And this kind of imitation cannot be related to the essence of memetics. Teachers only repeat the process of teaching the model essay in the past. Although students can grasp the grammatical points after splitting the whole essay, they still cannot know how to apply those knowledge. On the whole, this mechanical teaching method of English writing can hardly stimulate students' interest. Even though the multi-media teaching equipment has spread to a large extent, there are still many teachers who do not know how to combine it with the traditional English class. On the other hand, they do not understand how to develop the writing teaching even though they have already been familiar with the function of memetics, which is the limiting factor in the English writing teaching.

The Boring Writing Contents. At present, the materials of English writing are mainly from English textbooks. Although the materials are not always socialist-minded, they are relatively boring and cannot successfully combine with students' daily life. Especially under the influence of the traditional writing imitation method, students imitate the model essay not only in sentences, but also in contents. As a result, the students seldom brainstorm when they begin to write, which will deprive them of the opportunity of finding good writing materials. On the other hand, a language itself can only display its charm when it is put into the practical life. If students depart from their practical life, then the essays they write are lack of connotation, which is a vicious circle for English writing. It will be helpful to solve this problem if we apply the language memetics to the English writing teaching. That is because in the perspective of memetics, the English writing teaching emphasizes the fact that students should create their own writing materials after they have grasped the basic knowledge of English writing. And only in such a process can the charm of English be fully displayed.

\section{The Concrete Improving Measures of Breaking the Limiting Factors of Memetics in English Writing Teaching Process}

Enriching the Teaching Methods. The process of applying memetics to the English writing teaching can be divided into four stages: input; memory; output; interaction. In fact, from the perspective of the development of memes, the teacher should intensify the frequently-used words and phrases in writing in the stages of input and memory. And we can understand "words and phrases" as memes, and in this way students can lay a solid foundation for their writings after absorbing those expressions. This step is in fact the traditional process of writing teaching. In addition, when it comes to choosing the input materials, the teacher should expand the forms of the 
same materials and try to select those materials that can stimulate students' learning interest and are easy to be memorized. In this way can they have the proactivity of memorizing the writing materials. Therefore, for the writing teaching, we should change the current teaching method, and try to take advantage of the multi-media teaching equipment to practice the students' divergent thinking. For example, students can be encouraged to extract the keywords, and then combine them into sentences and texts, in order to grasp the rules of writing. Therefore they will be eager to express their opinions actively. The "imitation", in which words and phrases can be inputted into the students' brains and students can regroup them, only remains at the syntactic stage. Therefore, the students' creativity can be guaranteed, which is the essence of English writing teaching in the perspective of language memetics.

Updating the Writing Materials by Combining Them with the Current Society. The aim of learning English is to improve our ability of communicating with others on the premise of meeting the need of personal development. As far as the English writing teaching be concerned, only updating the writing materials on the basis of the characteristics of times can the English writing teaching level be enhanced. On the premise of lacking the professional writing reference materials, what teachers should do is to combine with the current social affairs and choose the most suitable writing materials which can exercise students' writing ability. As for the non-mainstream culture, teachers should try their best to shield it. In addition, what teachers should also do is to provide students with outstanding writing ability except the basic grammatical points, which is suitable for them. In addition, the teacher should also encourage students to break the limitation of the class teaching and try to find the writing materials from their own life and express their own views and emotions from the perspective of the current living condition. Teachers should help students to analyze the values of writing materials from different aspects because those materials can be very helpful for improving their comprehensive English quality.

Paying Attention to the Accumulation of Knowledge. The English writing teaching cannot ignore the function of accumulation. Even when the language memetics is applied to the English writing teaching, teachers should have a clear understanding about the accumulation in the process of writing. The "accumulation" mentioned here is not merely related to the recitation of good sentences and model essays. Only returning back to the starting point of learning English, i.e. the vocabulary, can students' foundation of the language be laid in a solid way. Moreover, only after the students have accumulated enough vocabularies and mastered the basic grammatical structures, can they successfully express what they want to say. For a long time in the past, teachers have always taught students to memorize the model essays mechanically. As a matter of fact, reciting itself is of no use for improving most students' writing skills. The reason is that they do not know how an article is written down once the model essay is not in their hand. Just as what we have mentioned in the above text, teaching model essays mechanically cannot stimulate students' interest for English writing. Therefore, we need to extend the model of accumulating the English writing materials in order to ensure the teaching effect. In particular, we should remind students of the importance of accumulating some English idioms, which may easily become the shining point in their essays and therefore gain them extra scores. Moreover, teachers can even take off some time before the class to show students' accumulated materials, in which the most important point is that all teaching methods should begin from students' interest and try to find the students' interest point. What we should avoid is the over-emphasizing "reciting" just for the purpose of memorization.

Improving the Proofreading of Students' Composition. Correcting a composition can be regarded as a feedback after the writing process. In the past, it is the teacher himself who played the role of correcting the compositions. In this way, the teachers had heavy workload and could not give relevant guidance according to each student's problems in the writing process. On the contrary, under the perspective of language memetics, the English writing teaching should try to encourage the peer-editing process, in which each student can have the opportunity of finding the shining point of others' composition. It should be noticed that in the process of peer-editing, the teacher should teach students some techniques of correcting others' essays, for example, how to find the most error-prone words and expressions, and the similar grammatical points which are easy to be 
confused. Only after these techniques are taught to the students, can they deepen their writing in the process of correcting their classmates' composition. Moreover, they will consciously avoid the misusage of the similar vocabularies and grammatical points in their future writing practice.

\section{Conclusion}

The teaching of English writing is of vital importance in the whole English teaching. It has also been a difficult point in basic English teaching at home in recent years. We are facing the problem of how to improve the English writing teaching and change the traditional teaching method. The language memetics can not only eliminate various kinds of problems in the English writing teaching process, but also enhance students' interest in learning English. In addition, it can help teachers to find out a more suitable method of teaching English writing, which will bring more enlightenment and assistance to the English teaching in our country. Based on the author's own experience, this paper puts forward the conclusion of the reform of English writing teaching from the perspective of language memetics, and it may be helpful to improve the current situation of English teaching.

\section{References}

[1] Huang ling. The "reciting - imitating" English writing teaching model under the perspective of memetics. [D].Fujian Normal University, 2009.

[2] Wang Xu. The study of high school English imitation writing teaching under the perspective of memetics. [D].Heilongjiang University, 2012.

[3] Xia Yuyu. The college English writing teaching under the language perspective of memetics. [J].Journal of Jiaozuo University, 2010, 01: 128-130.

[4] Liu Bin. The CET 4 writing teaching under the perspective of memetics. [J]. Journal of Hebei Polytechnic University (Social Sciences), 2010,04:184-186.

[5] Zhang Lixia. The college English writing teaching under the perspective of memetics. [J].Journal of Xingtai College, 2010, 04: 49-51.

[6] Lei Yulan. The college English writing teaching under the perspective of memetics. [J].China Electric Power Education, 2010, 33: 214-216.

[7] Li Ying. The high school English imitation writing teaching under the perspective of memetics. [D].Hunan Normal University, 2010.

[8] Sun Qing. The synonymy isomerism strategy of language memes and the English writing teaching. [A].the innovative research on foreign language education and the development of translation(the 5th volume) [C].:,2016:3.

[9] Lan Jinping. The Empirical Study of English Writing Teaching "Reciting-Imitating-Innovating" Model from the Perspective of Memetics. [D]. North China Electric Power University, 2014.

[10]Zhang Ling. The Application of Reciting and Imitation in the English Writing Teaching in Vocational Education from the Perspective of Memetics [D].Shandong Normal University,2014. 